\title{
Adolescents’ Interpersonal Relationships with Friends, Parents, and Teachers When Using Facebook for Interaction
}

\author{
Shih-Hsiung Liu ${ }^{1 *}$, Mei-Chun Yin², Tsung-Hsien Huang ${ }^{3}$ \\ ${ }^{1}$ Center for Teacher Education, National Changhua University of Education, Changhua, Taiwan \\ ${ }^{2}$ Department of Education, National University of Tainan, Tainan, Taiwan \\ ${ }^{3}$ Tainan Municipal Jiali Junior High School, Tainan, Taiwan \\ Email: "shsiung@cc.ncue.edu.tw
}

Received March 18 (t) $^{\text {th }}$ 2013; revised April 20 $0^{\text {th }}$, 2013; accepted May $4^{\text {th }}, 2013$

\begin{abstract}
Copyright $\odot 2013$ Shih-Hsiung Liu et al. This is an open access article distributed under the Creative Commons Attribution License, which permits unrestricted use, distribution, and reproduction in any medium, provided the original work is properly cited.
\end{abstract}

\begin{abstract}
The purpose of the study is to investigate the adolescents' interpersonal relationships with friends, parents, and teachers when using Facebook for interaction. A total of 740 junior high school students were invited to fill in a questionnaire and 673 questionnaires were available. Data were analyzed using one-way analysis of variance and paired-samples t-test. The analytic result confirms that adolescents with high frequency use of Facebook for interactions can expand their interpersonal relationships with friends than those who with low frequency use, regardless of real-life or virtual relationships. However, their real-life interpersonal relationships with parents may weaken if overly use Internet tools for interactions. Another finding, eliminating the factor of the time on Facebook use, reveals that the adolescents' real-life interpersonal relationships are stronger than virtual interpersonal relationships, regardless of with friends, parents, and teachers. Combining the above two findings, it is worth noting that the real-life interaction with parents may reduce if overly use Internet tools for interactions. This study contributes to the literature by investigating the adolescents' relationships with friends, parents and teachers and indicates the potential program when adolescents using Facebook use for interaction. This study, thus, further recommends that parents should be concerned their children about Facebook use.
\end{abstract}

Keywords: Adolescents; Interpersonal Relationships; Facebook

\section{Introduction}

Internet access has changed people's lives, especially for communication with each other. Some studies have explored the effects of Internet technology use on social network (e.g. Bouillion Diaz, Thompson, \& DeGennaro, 2010). According to Lenhart, Purcell, Smith and Zickuhr (2010), more than 75\% American adolescents have at least one social webpage (e.g. Blog, Facebook) to share information and make contact with others. The Internet communication, taking Facebook for example, provides adolescents with opportunities to maintain the existing interpersonal relationships as well as to develop new friendships, according to a report by Mesch and Talmud (2006). For most adolescents, Internet communications seem to be a regular as well as important work in lives.

In Taiwan, Facebook use has also increasingly become an interesting work for adolescents. Based on a record from Facebook.com, supposedly, more than a half of Taiwanese adolescents ranging in age from 13 to 15 years, as a junior high school student, had experienced Facebook use. Facebook is different from traditional Internet communication tools. Zuckerburg, the founder of Facebook, stresses that Facebook is not only a dating tool but also a function in which users can expand their friendships to online. Thus, people who use Facebook can easily build online relationships. Subrahmanyam, Reich, Waechter and Espinoza (2008) indicated that adolescents increasingly build their social relationships with known friends through communication on the Facebook, along with routine contact in daily lives. Suwannatthachote and Tantrarungroj (2012) also indicated that students communicate with friends for both academic and social discussions on Facebook. Since Facebook is a popular social tool, more and more people apply and use it. Once adolescents know their parents or teachers use Facebook, not everyone will invite or add their parents and teachers as Facebook friends. Even though people recognizes that adolescents interacting with parents and teachers in real life should be much more than on Internet, Facebook, as mentioned, providing more opportunities to make contact with known people, make virtual interactions become frequent due to some reasons, such as lack of face-to-face time, space limitation, or being shy to say something in front of others.

Interpersonal relationships are a network in which people share themselves and trust the value of mutual interaction. The positive interpersonal relationships provide people with opportunities to support others and receive others' supports on social works and individual emotion, and further to form a cordial atmosphere of intimacy and mutual caring (Snell \& Janney, 2000). In terms of adolescents, they desire to be recognized as adults, autonomous members of society, and to obtain the rights and privileges, especially from their friends, parents, and teachers. However, adolescents are sometimes too shy to express themselves in front of others because grownups have now be- 
come the operating standard for acting more maturely. McKenna, Green and Gleason (2002) express that less interactive presence can reduce possible uncomfortable feelings during face-to-face interaction. People will open their mind when connecting with others on the Internet (Suler, 2004). Comparing to real life, people are more willing to make a self-disclosure on the Internet than in the real-life situation (McKenna et al., 2002). Thus, Facebook use can facilitate adolescents to voluntarily express their thoughts, emotions, beliefs, and attitude towards life and to seek for identification from others, and further to tie with their friends through Internet communication. Reasonably, Facebook use has positive effects on adolescents' interpersonal relationships. Due to different types of interactions in real-life and virtual situation, real-life and virtual interpersonal relationships may be developed separately.

Furthermore, the adolescents' interactions with friends, parents, and teachers may differ, resulting in different interpersonal relationships with different objects. According to a Taiwanese study by Chou and Peng (2007), the majority of Taiwanese adolescents did not tell their parents about their online dating; these adolescents, however, trusted the built online friendships. boyd and Hargittai (2010) reported that the majority of young adult users of Facebook are engaged with managing their privacy settings. Some students would be aghast if they knew the kinds of information that their instructors could collect about them on Facebook. Moreover, more time the adolescents spend on Internet interaction, higher trustfulness they hold for net-friends, which means more dangerous they would emerge in situation (McCarty, Prawitz, Derscheid, \& Montgomery, 2011). The above literature refers to adolescents' various interactions with different objects. The frequency of using Facebook for interactions seems to also impact adolescents' interpersonal relationships with friends, parents, and teachers.

In sum, whether Taiwanese adolescents use overly Facebook may relate to their real-life/virtual relationships with different interactive objects. Based on the above discussions, the first research question is addressed as "What are the differences in adolescents' real-life/virtual interpersonal relationships with friends, parents, and teachers between a variety of frequencies of using Facebook for interactions?”

Moreover, some people do not agree with the benefits of Facebook on interpersonal relationships and believe that health interpersonal relationships should be built and maintained on people's real life. Internet social contacts may reduce face-toface interaction with others and further neglect to foster social interpersonal skills. Louv (2005) argued that overly online interaction increases lack of experiences in social interaction with others. Whitty (2008) also indicated that online interaction tends to use paralinguistic and emotional symbols, resulting in lack of interactive presence, and even, additional aggressive language. Martusewicz (2010) worried that this so-called social networking, resulting from Facebook use, as a students' capacity may not be able to deal, intelligently, face-to-face with parents, and even other teachers.

Kraut, Patterson, Lundmark, Kiesler, Mukopadhyay and Scherlis (1998) initially argued that online interaction weaken social relationships with others. However, they investigated the same samples after three years and indicated that the previous negative effects have disappeared. The latter study concluded that online interaction has positive effects on social participation. Accompanying with the positive effects, adolescents' interpersonal relationships increasingly expand. Desjarlais and Willoughby (2010) conducted a longitudinal study about adolescents' friendships in using Internet to make friends and indicated that online interaction with their known friends benefits their real-life interpersonal relationships. As for contacts with strangers, a study by Gross (2004) indicated that the built relationships with strangers were weak and helpless for interpersonal relationships. McKenna, Green and Gleason (2002) explored whether the real-life interpersonal relationships were weaken while people favor online interaction with others and reported that $95 \%$ of the participants who usually make contact with others through Internet did not reduce social interaction with family and friends in daily lives. The study also revealed that $88 \%$ of the participants who overly use Internet communication did not change the way to interact with their family and friends. The above perspectives seem to reveal that adolescents' real-life and virtual relationships with others tend to be consistent when using Facebook for interactions.

These previous studies did not sufficiently identify that Internet communication by Facebook use benefits adolescents' interpersonal relationships, especially with parents and teachers. Online interaction may weaken social relationships with others in the life, In terms of an adolescent ranging in age from 13 to 15 years, parents and teachers are still important people in their life. An adolescent with health social relationships with parents as well as teachers are still necessary. However, few studies involved the comparison between real-life relationships and virtual relationships in parents and teachers whom adolescents use Facebook to interact with. The second research question is addressed as "What are the differences in Taiwanese adolescents' interpersonal relationships with friends, parents, and teachers between real-life and virtual relationships when using Facebook for interaction?”

\section{Methods}

A survey method was conducted to determine the differences of adolescents' real-life/virtual interpersonal relationships with friends, parents, and teachers when using Facebook for interaction. Before the survey, four professors as well as four junior high school teachers were invited to examine the initiate questionnaire and a group of 100 junior high school students were recruited to fill in the revised questionnaire. In final, 740 junior high school students who have experiences of using Facebook and whose Facebook friends include their parents and teachers, were invited to fill in the validated questionnaire. Through examined carefully, 674 questionnaires were available.

Two assessments were applied in this questionnaire. The Real-life Interpersonal Relationship (RIR) assessed adolescents' real-life interpersonal relationships with friends, parents, and teachers. The Virtual Interpersonal Relationship (VIR) assessed adolescents' virtual interpersonal relationships with friends, parents, and teachers. The items of interpersonal relationships included self-discourse, sharing information, receiving help, and emotional support for others. The RIR and VIR have 12 items respectively. Examples of the items in the RIR were "I am willing to make a self-discourse with my friends in life", "I am willing to share information with my parents", and "I am willing to express my feeling with my teachers". Examples for VIR items were "I am willing to make a self-discourse with my online friends on Facebook", "I am willing to share information with my parents through Facebook", and "I am 
willing to express my feeling with my teachers through Facebook".

Each item was assessed using a five-point scale with $5=$ "very strongly agree" and 1 = "very strongly disagree". Through reliability analyzed, the reliability coefficient of RIR was .792 for "with friends", .882 for "with parents", .811 for "with teachers", and .915 for total RIR assessment. Additionally, the reliability coefficient of VIR was .891 for "with friends", .923 for "with parents", .930 for "with teachers", and .907 for total VIR assessment.

Moreover, most Taiwanese adolescents need to face the entrance exams, may spend less time to interact with others by Facebook. Generally, they only spend a half hour lurking internet and posting/responding one or two piece of information in a day. This phenomenon results in that adolescents may not be able to assess what a frequency of using Facebook for interactions is. This study addressed a question, how many days per a week do you use Facebook for interacting with others, instead of frequency of Facebook interaction. In terms of life situation in Taiwan, it is reasonably supposed that more days Taiwanese adolescents use Facebook for, the higher frequency they interact with others online.

Data were analyzed using one-way analysis of variance (ANOVA) and paired-samples t-test. First, the ANOVA was applied to determine the differences in various interpersonal relationships with friends, parents, and teachers between a variety of frequencies of using Facebook for interactions. Second, paired-samples t-test was employed to explore the differences in real-life/virtual relationships with friends, parents, and teachers, respectively.

\section{Findings}

To determine the differences in adolescents' various relationships with friends, parents, and teachers between a variety of frequencies of using Facebook for interactions, one-way ANOVA technique was employed. Table 1 shows the means and $F$ value.

The analytic results reveal significant differences in "real-life interpersonal relationships with friends", "real-life interpersonal relationships with parents", and "virtual interpersonal relationships with friends" between a variety of frequencies of Facebook interactions. Regardless of real-life or real-life interpersonal relationships, the adolescents with high frequency use of Facebook for interactions have strong relationships with their friends, while have weak relationships with their parents. These findings indicate that Facebook interactions can facilitate adolescents' real-life relationships with their friends; however, overly Facebook use may weaken the relationships with their parents in the life. The adolescents' virtual relationships with

Table 1.

One-way anova on the means of various interpersonal relationships with friends, parents, and teachers.

\begin{tabular}{|c|c|c|c|c|c|c|c|}
\hline Dependent variables & Frequencies & Number & Submeans & $M$ & $F$ & $p$ & Scheffe \\
\hline \multirow{4}{*}{$\begin{array}{l}\text { real-life interpersonal relationships } \\
\text { with friends }\end{array}$} & 1 - 2 days/week (A) & 253 & 3.83 & \multirow{4}{*}{3.91} & \multirow{4}{*}{2.855} & \multirow{4}{*}{.035} & \multirow{4}{*}{$\mathrm{D}>\mathrm{A}$} \\
\hline & 3 - 4 days/week (B) & 149 & 3.91 & & & & \\
\hline & 5 - 6 days/week (C) & 85 & 3.90 & & & & \\
\hline & every day (D) & 187 & 4.03 & & & & \\
\hline \multirow{4}{*}{$\begin{array}{l}\text { real-life interpersonal relationships } \\
\text { with parents }\end{array}$} & 1 - 2 days/week (A) & 253 & 3.66 & \multirow{4}{*}{3.49} & \multirow{4}{*}{4.658} & \multirow{4}{*}{.003} & \multirow{4}{*}{$\mathrm{A}>\mathrm{D}$} \\
\hline & 3 - 4 days/week (B) & 149 & 3.43 & & & & \\
\hline & 5 - 6 days/week (C) & 85 & 3.47 & & & & \\
\hline & every day (D) & 187 & 3.30 & & & & \\
\hline \multirow{4}{*}{$\begin{array}{l}\text { real-life interpersonal relationships } \\
\text { with teachers }\end{array}$} & 1 - 2 days/week (A) & 253 & 3.35 & \multirow{4}{*}{3.23} & \multirow{4}{*}{2.203} & \multirow{4}{*}{.087} & \multirow{8}{*}{$\begin{array}{l}\mathrm{D}>\mathrm{A} \\
\mathrm{C}>\mathrm{A} \\
\mathrm{B}>\mathrm{A}\end{array}$} \\
\hline & 3 - 4 days/week (B) & 149 & 3.27 & & & & \\
\hline & 5 - 6 days/week (C) & 85 & 3.18 & & & & \\
\hline & every day (D) & 187 & 3.17 & & & & \\
\hline \multirow{4}{*}{$\begin{array}{l}\text { virtual interpersonal relationships } \\
\text { with friends }\end{array}$} & 1 - 2 days/week (A) & 253 & 3.44 & \multirow{4}{*}{3.76} & \multirow{4}{*}{20.467} & \multirow{4}{*}{.000} & \\
\hline & 3 - 4 days/week (B) & 149 & 3.86 & & & & \\
\hline & 5 - 6 days/week (C) & 85 & 3.84 & & & & \\
\hline & every day (D) & 187 & 4.05 & & & & \\
\hline \multirow{4}{*}{$\begin{array}{l}\text { virtual interpersonal relationships } \\
\text { with parents }\end{array}$} & 1 - 2 days/week (A) & 253 & 2.31 & \multirow{4}{*}{2.35} & \multirow{4}{*}{0.406} & \multirow{4}{*}{.749} & \\
\hline & 3 - 4 days/week (B) & 149 & 2.43 & & & & \\
\hline & 5 - 6 days/week (C) & 85 & 2.37 & & & & \\
\hline & every day (D) & 187 & 2.33 & & & & \\
\hline \multirow{4}{*}{$\begin{array}{l}\text { virtual interpersonal relationships } \\
\text { with teachers }\end{array}$} & 1 - 2 days/week (A) & 253 & 2.51 & \multirow{4}{*}{2.64} & \multirow{4}{*}{2.132} & \multirow{4}{*}{.095} & \\
\hline & 3 - 4 days/week (B) & 149 & 2.71 & & & & \\
\hline & 5 - 6 days/week (C) & 85 & 2.66 & & & & \\
\hline & every day (D) & 187 & 2.73 & & & & \\
\hline
\end{tabular}


parents are also weakest among all types of interpersonal relationships $(M=2.35)$.

Furthermore, Table 2 shows the analytic results of pairedsamples t-test. It reveals significant differences in both real-life and virtual interpersonal relationships, regardless of with friends, parents, and teachers. Specifically, the adolescents' real-life interpersonal relationships are stronger than virtual interpersonal relationships $(t>0, p<.05)$. That is, even though Taiwanese adolescents use Facebook to make contact with their friends, parents, and teachers, they still maintain strong relationships with others in the life.

\section{Conclusion and Discussion}

Based on the questionnaire analysis, the adolescents with high frequency use of Facebook for interactions build stronger both real-life and virtual interpersonal relationships with friends than those who are low frequency of Facebook use. The study result, as a perspective from Subrahmanyam et al. (2008), confirms that Facebook use can expand adolescents' interpersonal relationships with friends regardless of real-life or virtual relationships. However, overly use Internet may neglect the interactions with parents in the life, and even weaken the real-life relationships with their parents. The finding, as a worry from Martusewicz (2010), is worthy of noting and may imply a barrier in maintaining adolescents' real-life relationships with their families, even for development of interpersonal skills. Even though McKenna et al, (2002) indicated that most of the Facebook users did not reduce interaction with family in the life, but overly Facebook use may affect adolescents' real-life relationships with their parents. This study clarifies that Facebook use can strengthen adolescents' pre-existing social relationships with friends as well as facilitate their virtual relationships; however, adolescents' virtual relationships with parents are weak. Even, overly Facebook use will weaken interpersonal relationships with parents in the life.

In terms of Taiwanese adolescents, they usually establish contact with their friends through computers at home. When adolescents spend much time on the Facebook building online friendships, their real-life interactions with parents may reduce. These are the reasons why Taiwanese adolescents' interpersonal relationships with friends are strong and their real-life relationships with parents are weak when overly using Facebook.

Another finding in this study, eliminating the factor of the time on Facebook use, reveals that the adolescents' real-life interpersonal relationships, regardless of with friends, parents, and teachers, are stronger than virtual interpersonal relationships. As mentioned, online interaction with known people benefits people's social interpersonal relationships. McKenna, et al. (2002) also reported that Facebook users who usually establish contact with others through Internet do not reduce social interaction with family and friends on daily lives. This study reveals that real-life relationships with friends, parents and teachers are stronger than virtual relationships. That is, it can be identified that Taiwanese adolescents' interpersonal interactions with friends, parents and teachers were still maintained, and not to be reduced due to using Facebook for interactions. However, this study further indicates that, differing from the perspective from McKenna, et al., adolescents who overly use Facebook for interaction would weaken real-life interpersonal relationships with their parents.

Combining the above two study findings, Facebook use can
Table 2.

Summary for paired-samples t-test result for real-life/virtual relationships with friends, parents, and teachers.

\begin{tabular}{ccccccc}
\hline $\begin{array}{c}\text { Dependent } \\
\text { variables }\end{array}$ & $\begin{array}{c}\text { Interpersonal } \\
\text { relationships }\end{array}$ & $\mathbf{N}$ & $\boldsymbol{M}$ & $\boldsymbol{S D}$ & $\boldsymbol{t}$ & $\boldsymbol{p}$ \\
\hline with & real-life & 674 & 3.91 & 0.70 & 4.916 & .000 \\
friends & virtual & & 3.75 & 0.88 & & \\
& real-life & & 3.49 & 1.01 & & \\
with & 674 & 2.35 & 1.06 & & \\
parents & virtual & & 000 \\
with & real-life & & 3.26 & 0.82 & & \\
teachers & virtual & 674 & 2.63 & 0.98 & & \\
\hline
\end{tabular}

benefit Taiwanese adolescents' social relationships. The results of the study do not worry educators and parents yet. However, it is worth noting that the interaction with parents may reduce if overly use Internet tools for interactions. Based on Facebook use weakens adolescents' relationships with parents, this study echoes the study by Chou and Peng (2007) who indicated that the majority of Taiwanese adolescents did not tell their parents about their online dating. This study contributes to the literature by investigating the adolescents' relationships with friends, parents and teachers and indicates the potential program when adolescents using Facebook use for interaction. This study, thus, further recommends that parents should be concerned their children about Facebook use.

\section{Acknowledgements}

The authors would like to thank the National Science Council, Taiwan for financially supporting this research under Contract No. NSC 101-2410-H-018-030.

\section{REFERENCES}

Bouillion Diaz, L., Thompson, C. C., \& DeGennaro, D. (2010). Leisure and technological influences. In M. B. Spencer, D. Swanson, \& M. Edwards (Eds.), Adolescence: Development during a global era. Philadelphia: Elsevier.

boyd, d., \& Hargittai, E. (2010). Facebook privacy settings: Who cares? First Monday, 15.

Chou, C., \& Peng, H. (2007). Net friends: Adolescents' attitudes and experiences vs. teachers' concerns. Computers in Human Behavior, 23, 2394-2413. doi:10.1016/j.chb.2006.03.015

Desjarlais, M., \& Willoughby, T. (2010). A longitudinal study of the relation between adolescent boys and girls' computer use with friends and friendship quality: Support for the social compensation or the rich-get-richer hypothesis? Computers in Human Behavior, 26, 895-905. doi:10.1016/j.chb.2010.02.004

Gross, E. F. (2004). Adolescent internet use: What we expect, what teens report. Applied Developmental Psychology, 25, 633-649. doi:10.1016/j.appdev.2004.09.005

Kraut, R., Patterson, M., Lundmark, V., Kiesler, S., Mukopadhyay, T., \& Scherlis, W. (1998). Internet paradox: A social technology that reduces social involvement and psychological well-being? American Psychologist, 53, 1017-1031. doi:10.1037/0003-066X.53.9.1017

Lenhart, A., Purcell, K., Smith, A., \& Zickuhr, K. (2010). Social media and young adults. Pew Internet \& American Life Project. http://www.pewinternet.org

Louv, R. (2005). Last child in the woods: Saving our children from nature-deficit disorder. Chapel Hill, NC: Algonquin Books of Chapel Hill.

Martusewicz, R. A. (2010). Facebook and me, or how I spent my summer vacation. Educational Studies, 46, 447-449. 


\section{S. H. LIU ET AL.}

McCarty, C., Prawitz, A. D., Derscheid, L. E., \& Montgomery, B. (2011). Perceived safety and teen risk taking in online chat sites. CyberPsychology, Behavior, and Social Networking, 14, 169-174. doi:10.1089/cyber.2010.0050

McKenna, K. Y. A., Green, A. S., \& Gleason, M. E. J. (2002). Relationship formation on the Internet: What's the big attraction? Journal of Social Issues, 58, 9-31. doi:10.1111/1540-4560.00246

Mesch, G., \& Talmud, I. (2006). Online friendship formation, communication channels, and social closeness. International Journal of Internet Science, 1, 29-44.

Snell, M., \& Janney, R. (2000). Teachers' guide to inclusive practices: Social relationships and peer support. Baltimore: Paul H. Brookes Publishing.

Subrahmanyam, K., Reich, S. M., Waechter, N., \& Espinoza, G. (2008).
Online and offline social networks: Use of social networking sites by emerging adults. Journal of Applied Developmental Psychology, 29, 420-433. doi:10.1016/j.appdev.2008.07.003

Suler, J. (2004). The online disinhibition effect. CyberPsychology and Behavior, 7, 321-326. doi:10.1089/1094931041291295

Suwannatthachote, P., \& Tantrarungroj, P. (2012). How facebook connects students' group work collaboration: A relationship between personal Facebook usage and group engagement. Creative Education, 3, 15-19. doi:10.4236/ce.2012.38B004

Whitty, M. T. (2008). Liberating or debilitating? An examination of romantic relationships, sexual relationships and friendships on the Net. Computers in Human Behavior, 24, 1837-1850.

doi:10.1016/j.chb.2008.02.009 